\title{
El Archivo Documental, Administrativo e Histórico de la Administración de Parques Nacionales en el Museo de la Patagonia "Dr. Francisco P. Moreno"
} Documentary, Administrative and Historical Archive of the Administration of Nationals Parks, in the Patagonia Museum "Dr. Francisco P. Moreno"

\section{Giulietta Piantoni and María Alejandra Pupio}

\section{Q OpenEdition}

\section{Journals}

Electronic version

URL: http://journals.openedition.org/corpusarchivos/1807

DOI: 10.4000/corpusarchivos.1807

ISSN: 1853-8037

Publisher

Diego Escolar

\section{Electronic reference}

Giulietta Piantoni y María Alejandra Pupio, «El Archivo Documental, Administrativo e Histórico de la Administración de Parques Nacionales en el Museo de la Patagonia "Dr. Francisco P. Moreno" », Corpus [En línea], Vol. 7, No 1 | 2017, Publicado el 30 junio 2017, consultado el 01 mayo 2019. URL http://journals.openedition.org/corpusarchivos/1807; DOI : 10.4000/corpusarchivos.1807

This text was automatically generated on 1 May 2019.

Licencia Creative Commons: Atribución-NoComercial 2.5 Argentina (CC BY-NC 2.5 AR) 


\section{El Archivo Documental,} Administrativo e Histórico de la Administración de Parques Nacionales en el Museo de la Patagonia "Dr. Francisco P. Moreno" 1

Documentary, Administrative and Historical Archive of the Administration of Nationals Parks, in the Patagonia Museum "Dr. Francisco P. Moreno"

Giulietta Piantoni and María Alejandra Pupio

\section{EDITOR'S NOTE}

Fecha de recepción del original:

Fecha de aceptación para publicación:

\section{Introducción y contexto}

El archivo del que nos ocupamos en este trabajo tuvo su origen en las prácticas burocráticas de la administración nacional. A mil seiscientos kilómetros de la capital de la Argentina, el Museo de la Patagonia cumplía con los procedimientos públicos y estadísticos que establecía la oficina central de la Dirección de Parques Nacionales de la cual dependía (hoy Administración de Parques Nacionales APN), a pesar de los escasos recursos económicos y humanos con que se dotó a esta institución. Este museo fue creado en 1939 e inaugurado con el conjunto edilicio del Centro Cívico de San Carlos de Bariloche 
el 17 de marzo de 1940. El primer conjunto de piezas históricas, arqueológicas y etnográficas que se expusieron, se adquirieron por medio de una transacción comercial de quien fue su primer director, Enrique Amadeo Artayeta (Piantoni 2015; Pupio 2011).

2 Como la mayor parte de los museos de fines del siglo XIX y principios del XX, su administración, aunque ligada íntimamente a la figura de su promotor, cumplió con ciertos requisitos que permitieron registrar e inventariar el arribo y movimiento interno y externo de las colecciones. Como señala Podgorny, esto requirió la trasformación de estos objetos en papel para permitir el recorrido científico, que no se hacía en las salas y en los depósitos sino en el sistema de inventario y de registro a través de "fichas" o "tarjetas", a lo que se sumaban sus fotografías y los planos de aquellos especímenes naturales y objetos arqueológicos recolectados en el campo (Podgorny 2011). En este caso de estudio, el Archivo Documental fue iniciado por su primer director, de acuerdo a las normas burocráticas emanadas de la administración nacional y de los usos técnicos referidos al manejo de las colecciones, tanto en el área de depósito como en las salas de exhibición. Esta práctica de organización y clasificación para objetos, plantas, animales y documentos históricos en los museos constituyeron la infraestructura epistémica moderna al crear métodos sistemáticos de catalogación compartidos (Farro 2013; García 2012; Hedstrom, Margaret y King 2006). Para el siglo XX estas prácticas eran compartidas a partir de la circulación de información a través de una amplia red de sociabilidad establecida por los directores de museos de ciudades de provincias y territorios nacionales a través de la correspondencia privada y pública.

Los diversos funcionarios del Museo de la Patagonia han realizado dispares esfuerzos para acrecentar el acervo del Archivo a través de la producción propia de la administración, la obtención de donaciones, el rescate de material de otras dependencias y la colaboración con distintas instituciones públicas y privadas. Este Museo es, en la Argentina, el único en su tipo que se encuentra dentro de un Parque Nacional. En cuanto a archivos históricos y documentales, la administración posee otro gran reservorio en su casa central en la ciudad de Buenos Aires, que en la actualidad se encuentra en un proceso de centralización del material, dadas las dimensiones de la institución y la dispersión de la documentación. Como consecuencia de estas historias institucionales, el Archivo de Nahuel Huapi es el único que constituye una unidad para su consulta en el conjunto de los parques nacionales. 


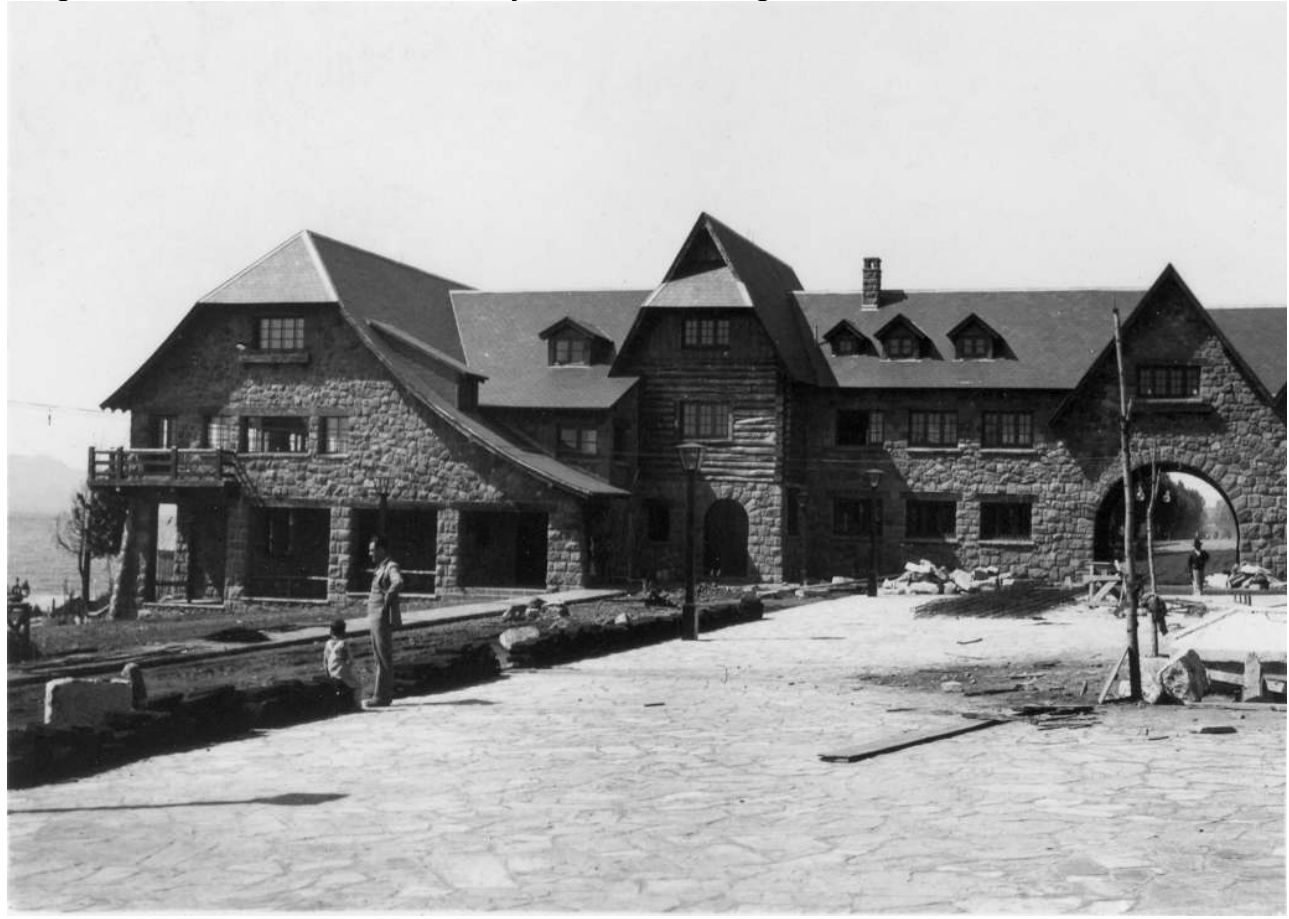

Fuente: Col. Meelboom. Archivo Documental Museo de la Patagonia.

Esta excepcionalidad del Museo y su Archivo ha producido el efecto de convertirse en receptor de material documental de diversos departamentos y divisiones. Es por esto que dentro de los fondos que resguarda posee materiales de otras dependencias del Parque Nacional Nahuel Huapi e, incluso, de otros parques. A la fecha, el Archivo se encuentra en proceso de reconfiguración y restructuración de su organización interna, con la posibilidad de subdividirse en tres archivos diferentes: histórico, institucional APN y administrativo del Museo.

En las páginas que siguen se describen las características generales de cada conjunto prestando atención especialmente al fondo administrativo del Museo, cuyas características permiten avanzar en la búsqueda de respuestas sobre las posibilidades que presentan los archivos documentales para la historia de los museos, de las ciencias y de las prácticas culturales del siglo XX (Pegoraro y Spoliansky 2013). Fuentes documentales como las aquí presentadas, aunque fragmentarias, no conservadas originalmente como documentos históricos, sino producto de prácticas burocráticas de la administración estatal, permiten dar cuenta de las tareas de gestión, los recursos y de los agentes que estaban vinculados con la gestión del Museo. Si bien este tipo de documentos han empezado a relevarse para distintas regiones del país, aún resta una revisión de estos repositorios para comprender un proceso más general. En el caso de la historia de los museos, este tipo de archivos permite un enfoque microhistórico para analizar a estas instituciones desde una perspectiva compleja que evite entenderlas solo como herramienta del Estado o como mera obsesión individual de sus promotores (Podgorny 2013). En especial permite también comprender la historia de los espacios en los que estas acciones tenían lugar, con la diversidad de sus características, objetivos y prácticas. 


\section{¿Qué y cómo se guarda?}

6 En general el Archivo del Museo de la Patagonia reviste una dificultad básica que se desprende de la diversidad de criterios adoptados a lo largo del tiempo por distintos funcionarios del Parque Nacional. Como señalamos previamente, un conjunto de la colección en papel lo compone el Archivo Documental. Gran parte de él aún no se encuentra inventariada, ni catalogada, y no se puede dar cuenta del volumen total y de sus diversos fondos por no encontrarse resguardadas en un único lugar. Incluso colecciones como las de otras dependencias de la APN se depositan en bolsones cerrados en cuarentena por lo que se desconoce su contenido, a lo que se suma que a la fecha los documentos se encuentran resguardados en diversos sectores del Museo. Los mismos han sido colocados en distintos depósitos y salas de reserva, dependiendo de su estado de conservación y valor patrimonial. Es paradójico, como dicen Irina Podgorny y Taniana Kelly (2012, p. 16), que sean las instituciones como estas, que fueron fundadas con el objetivo de resguardar la historia de la ocupación del territorio nacional, las que hallan descuidado lo que refiere a su propia historia. Es esta entropía de los archivos a la que alude Podgorny (2011) la que caracterizó, y en alguna medida lo sigue haciendo,. Esperando modificar este destino que parece ineludible, actualmente, una sala única de reserva del Archivo Documental se encuentra en un alto grado de avance.

7 Como se señaló previamente, el Archivo Documental posee tres fondos, uno de ellos vinculado a la historia del Museo y el otro a la Administración del Parque Nacional Nahuel Huapi. Respecto al primero, el Fondo Documental Administrativo interno del Museo (1938-2007) tiene la gran potencialidad de permitir, en primer lugar, la reconstrucción de su historia institucional. Entre los documentos reservados en la institución se puede acceder a libros, notas y cartas administrativas, actas, listados, pedidos de donaciones, archivos administrativos de la Dirección de Museos Regionales -creada con la intención de multiplicar la experiencia de Nahuel Huapi-, anales, memorias, planillas, expedientes, presupuestos, fotos, planos, cuadernos copiadores, disposiciones, mapas, manuscritos, periódicos, remitos, telegramas, inventarios, informes, etc. Además, correspondencia personal de los directores de la institución, producción científica de los mismos y de las tareas realizadas por sus empleados. 
Imagen $\mathrm{N}^{\circ} 2$ - Libro de inventario de bienes históricos.

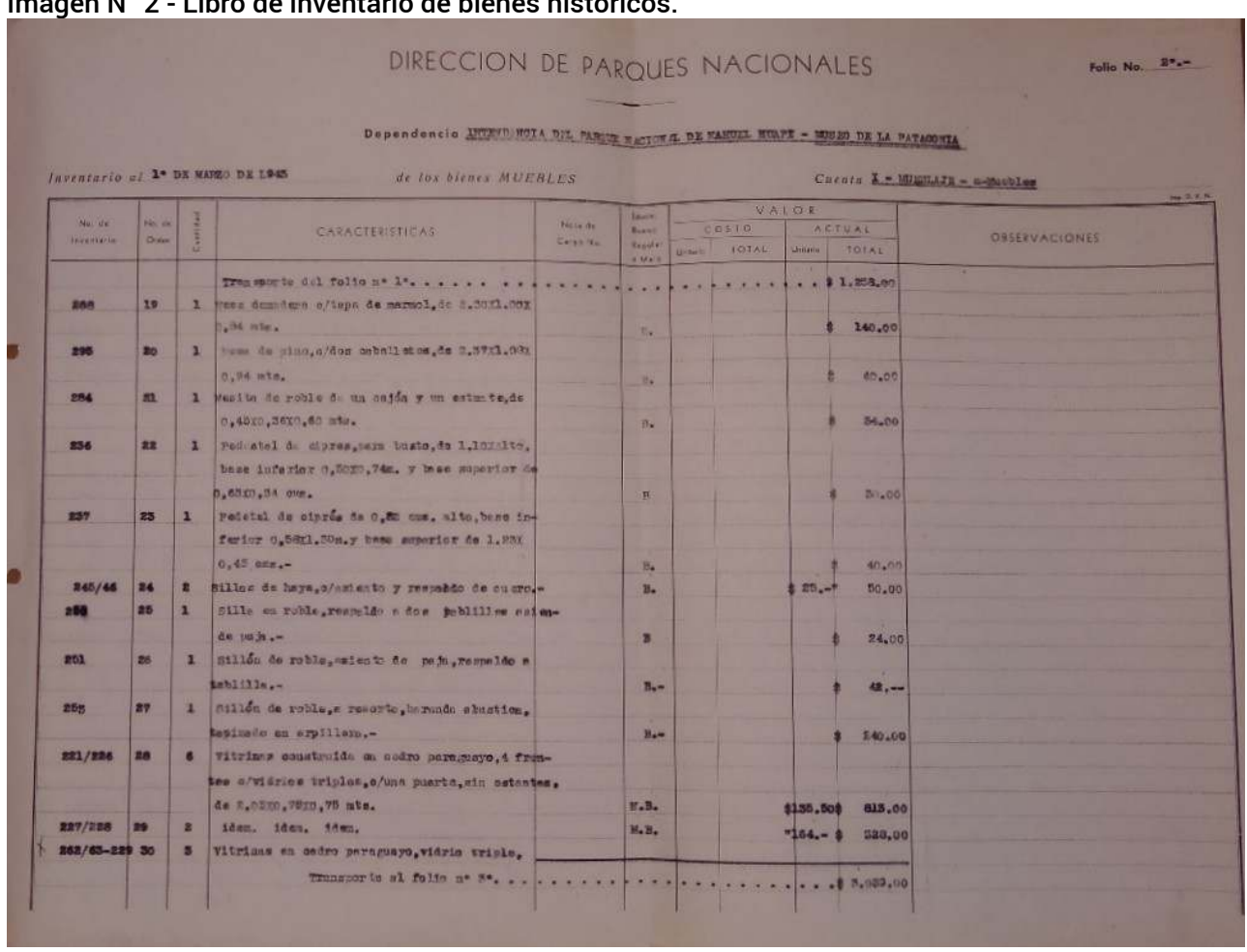

Fuente: Archivo Documental Museo de la Patagonia.

Los documentos del archivo testimonian el funcionamiento institucional mostrando distintas fases de las prácticas en un museo, tanto las estrategias desplegadas por su director para el ingreso de las colecciones, el diseño del presupuesto, la contratación del personal, los acuerdos con instituciones científicas, las decisiones de exposición (mobiliario, tipografías museográficas), la gestión de proyectos educativos y de actividades técnicas, como la taxidermia (Imagen $\mathrm{N}^{\circ} 2$ ). Por otro lado, resultan relevantes también para comprender la historia de las ciencias particulares que se desarrollaron en ese espacio institucional: la biología, la paleontología, la arqueología y la historia. En relación con estas últimas, este conjunto documental permite avanzar en el estudio de la articulación de dichas disciplinas científicas con el diseño museográfico tendiente a educar la mirada histórica de los visitantes (Piantoni 2015, 2016). 


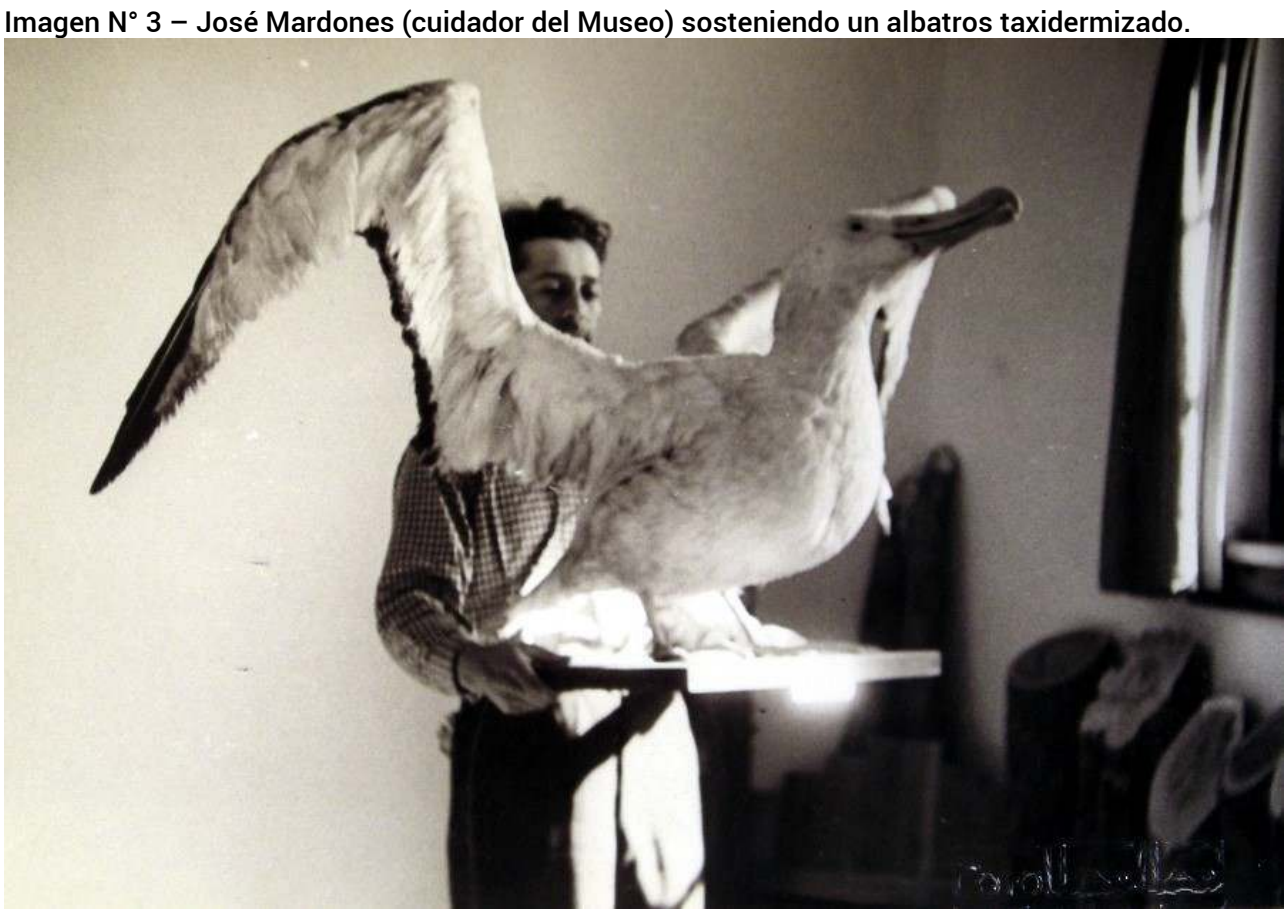

Fuente: Archivo Documental Museo de la Patagonia.

9 A esto se suma la posibilidad de conocer los cambios de la institución a través del tiempo. Como señala Farro (2013), estos archivos, pueden ser entendidos como una suerte de "biografía institucional" que permiten apreciar un proceso menos lineal, concreto y continuo de estas historias institucionales, más allá de las retóricas públicas desarrolladas por sus direcciones.

Respecto a la documentación del Parque Nacional, en el Fondo de la Seccional Isla Victoria se cuenta con material datado entre 1938 y 2009 que consiste en documentos, notas, biblioratos, expedientes de la seccional y del Centro de Instrucción de Guardaparques de la Isla, sobre todo de la década de 1970; carpetas (aproximadamente 65), planos y mapeos (alrededor de 298), fichas de pobladores, y sus ubicaciones, etc. Por otro lado, existen también fondos como los de la División de Obras del Parque Nacional; las fichas de jornaleros del Parque; actas de permisos precarios de ocupación y pastaje de 1934 en adelante, comunicados y boletines, entre otros materiales. Se han digitalizado también expedientes históricos que a la fecha siguen en circulación, y, dado su muy precario estado de conservación, se decidió preservar una copia digital de los mismos.

11 Antiguamente la documentación se reservaba en biblioratos con ganchos de metal que dañaron el formato papel por el roce y el óxido. Los agentes de conservación de la institución, han procedido al traslado de la misma a cajas antióxido, o de cartón simple, en las que se mantiene el orden original, colocando documento sobre documento, separados en algunos casos por papel japonés o de $\mathrm{pH}$ neutro. Cada caja puede contener entre 400 y 600 fojas, separadas por temática, y solo algunas se encuentran numeradas, rotuladas y foliadas.

El estado general de las colecciones puede ser considerado como bueno, si bien también se encuentran documentos conservados en muy buen estado, junto con otros de forma regular. Los mayores problemas detectados en su conservación provienen de los residuos de polvo y de la actividad de roedores que solo pueden ser prevenidas o mitigadas a 
través de la observación, monitoreo y control permanente de las colecciones. Por las condiciones climáticas de la región, no se han encontrado hongos o bacterias que pudiesen dañar de forma agresiva la documentación, más allá del desgaste por vejez o mal guardado.

Respecto al libre acceso a la información y la consulta, la institución ha intentado a lo largo de los años con esfuerzos disímiles proveer, a los investigadores de diversas disciplinas, de la información requerida sin comprometer la integridad de los originales, por lo que en su momento se fotocopiaron los fondos Francisco P. Moreno (1881-1930) y del ingeniero Emilio Frey (1897-1972) para la consulta regular. La falta de personal y por lo tanto de control, han derivado en el extravío de algunas de estas copias. Al momento no existe un inventario integral del contenido del archivo, pero se encuentra en proceso de cargado en base de datos digital y registro escrito (inventario) en planillas Excel. En general no se han adoptado criterios idénticos, por lo que cada colección posee una lógica propia. La biblioteca de la institución también cuenta con una amplia colección bibliográfica de consulta interna o de investigadores (libros que forman parte de las distintas colecciones, preservados por su carácter histórico y sus temáticas específicas, junto con cajas de actas, anales y memorias). Por su estado de conservación se ha decidido digitalizar los textos de mayor consulta.

\section{Las fotos aparte}

Los criterios personales adoptados a lo largo del tiempo han hecho que los documentos fotográficos fueran tratados por separado en lugar de adoptarse un criterio integrado. Existe desconocimiento de mucho del material manipulado o digitalizado. Por esta razón, la documentación fotográfica del Archivo Documental ha sido separada recientemente de su contexto y sistematizada por agentes del Museo, disociandola de los documentos que la acompañaban. Este proceso se ha realizado sin estar acompañado de referencias o inventarios. Esta tarea ha generado la dispersión de material y la imposibilidad de sostener un control estricto.

La llamada cristalización del instante visual nos permite pensar el material fotográfico como una herramienta de vital interés para poder observar, de forma complementaria, diversos discursos de época permitiéndonos revisar, comparar y complejizar los estudios históricos. Este tipo de material es fundamental para complementar las fuentes tradicionales, e incluso llegan a suplementar ausencias de documentos escritos (Mosches, Piantoni y Pierucci 2016).

En la Colección Moreno del Archivo del Museo de la Patagonia se encuentran fotografías originales y copias, de viajes e investigaciones de la Comisión de Límites con Chile o del Museo de La Plata, donde Francisco Pascasio Moreno se desempeñaba como Director. La Colección Frey se compone de material fotográfico, sobre todo relacionado con la Colonia Agrícola Pastoril de Nahuel Huapi -Emilio Frey, fue co-fundador y primer presidente del Club Andino Bariloche, intendente del Parque Nacional Nahuel Huapi entre 1934 y 1937 e intendente de la ciudad entre 1937 y 1939-, y del poblamiento que originó lo que hoy es la ciudad de Bariloche. Se destacan imágenes que reflejan las actividades recreativas y de montaña, actos y ceremonias, construcciones de hoteles, viviendas, instituciones, etc. El fondo documental cuenta con fotografías de la Comisión de Estudios Hidrológicos que fue presidida por Emilio Frey. Otros grupos de imágenes las componen diapositivas de fotos de distintos parques nacionales del sur y del Parque Nacional Nahuel Huapi mucho más 
recientes - décadas de 1970 y 1980-.. Otras colecciones reunen postales, o materiales fotográficos familiares. Además, se pueden encontrar en el Archivo fotografías de las salas, talleres, e instalaciones utilizadas para el control interno y publicidad institucional.

\section{¿Tirar o guardar? La conservación documental en la APN}

17 La Ley 15.930 prevé en su artículo $4^{\circ}$ la supervisión desde el Archivo General de la Nación, sobre todos los archivos administrativos nacionales. Dentro de este marco regulatorio entra el material del archivo de Casa Central de la Administración de Parques Nacionales. Los decretos 232/79 y 1571-81 son complementarios de la norma en lo que respecta a la eliminación de material y expurgos documentales.

18 A su vez, la Disposición HD 243/2015 del Directorio de la Administración de Parques Nacionales, respetando las leyes y decretos modificatorios antes mencionados y comprendiendo que la documentación de la APN conforma un fondo documental único y sensible, dispuso que todos los titulares de direcciones del organismo, intendencias y delegaciones regionales deben identificar el material de relevancia histórica y remitirlo a Casa Central. Considera que si se trata de documentación en expedientes activos, se podrá realizar una copia autenticada para resguardar el original. La norma destaca la necesidad de tomar medidas preventivas para “(...) asegurar la conservación de los documentos más antiguos que hacen a la identidad de esta Institución, otorgándoles el valor de documentación histórica" -fechada entre 1930 y 1989-. Esto es un claro avance en una institución sin una profunda cultura del resguardo documental.

En la actualidad el material resguardado se encuentra unificado en el Archivo del Museo, pero parte de la producción documental pertenece a secciones de la Administración de Parques Nacionales en la región, la propia archivalía del Museo, fondos particulares donados o adquiridos y colecciones de personalidades del Museo y la región, lo que debería generar una subdivisión. La realidad es que se lo considera - de la misma manera que a la Biblioteca- como subsidiarios de la actividad museística y no como una institución en sí misma. 
Imagen $\mathrm{N}^{\circ} 4$ - Notificación de resolución por permiso de caza al Señor Félix Anziano dentro del

Parque Nacional Nahuel Huapi.

Fuente: Archivo Documental Museo de la Patagonia.

Más allá de la voluntad personal y administrativa de cada gestión, puede observarse cómo históricamente dentro de las funciones asignadas a los Museos dentro de la APN no se encuentra enumerada la de resguardo de documentación. El reglamento general para los museos de los parques nacionales (aprobado por resolución 922D/60, actuación $\mathrm{N}^{\circ} 5532$ ), en su artículo $3^{\circ}$ estipula que el contralor administrativo deberá llevar registro del movimiento de expedientes, legajos, informes, notas y un libro de Registro y Catalogo de Inventario. El Reglamento del Museo del Parque Nacional Nahuel Huapi "Dr. Francisco P. Moreno"y, el del Museo del Parque Nacional Iguazú (Resolución 1191/62, actuación 4515/53), establecen entre las funciones del personal técnico administrativo la manipulación de los ficheros, expedientes, legajos, notas, informes, normas y en caso de no contar con personal específico para la Biblioteca, atender también sus requerimientos. Esto muestra que el material documental es entendido como subsidiario del quehacer museográfico y no como un elemento plausible de ser resguardado en sí mismo.

\section{El papel en la era digital}

Las copias digitales permiten poner en resguardo la documentación original dado que a menudo no son posibles de consultar a causa de las malas condiciones de conservación. La digitalización de archivos históricos acerca información a un público cada vez más amplio y multiplica el acceso, por lo que los interesados pueden consultar, ver, leer y estudiar los documentos desde los más diversos lugares (Demarchi 2015)

Esta premisa muchas veces está muy lejos de ser una realidad posible. Las causas pueden variar entre la falta de presupuesto, de espacio o de personal, la impericia, la falta de 
políticas institucionales de resguardo y salvaguarda y que la tarea recae frecuentemente en manos de voluntarismo no profesionalizado.

Como se mencionó más arriba, el desorden y la falta de un plan que rija las actividades a seguir, hacen que lo digitalizado hasta el momento en este Archivo responda a criterios disímiles y sea aún más dificultoso el pasaje de una tecnología a otra. Por ejemplo, se han realizado a lo largo del tiempo planillas Excel con criterios diversos e inventarios parciales, que no se corresponden con la información solicitada por la base de datos general de los objetos del Museo. El esfuerzo debe ser duplicado para complementar ambos sistemas.

En un informe realizado por el Archivo General de la Nación (Act. AGN 311/16), se ha recomendado el cese de este proceso de digitalización hasta no tener resueltos otros inconvenientes como los ya mencionados.

Si se pretende que el uso del Archivo sea abierto al público, debe ser autónomo, y por ello es indispensable un "manual de usuario" para la consulta y la puesta en valor de cada colección. Actualmente la falta de un índice que indique al usuario el modo de referenciar el registro complejiza el recuperar un documento posteriormente, dependiendo siempre de un informante clave para conocer la historia de cada colección y la proveniencia del material. A este respecto el AGN recomendó la adopción de normas internacionales para instituciones que preservan documentos de archivo (ISDIAH), para productores de documentos (ISAAR - CPF) y para documentos de archivo (ISAD - G), yendo, de lo general a lo particular y en sintonía con el cuadro de clasificación.

\section{Las opciones y posibilidades del Archivo}

Sobre la base de las fotografías, se pueden reconstruir fragmentos del pasado como actividades escolares, actos públicos o realizar un estudio de la evolución urbana. Respecto de los documentos escritos, también se puede trabajar en torno a la relación entre administración central y las administraciones regionales.

Un tipo documental que abunda en el Archivo es el material epistolar (Caldo y Fernandez 2009; Pupio 2013), que permite observar elementos de los más variados si se comprende que la producción de estas fuentes se dio en un marco institucional y burocrático en el que son observables dos niveles. Por lado, lo administrativo y el cumplimiento de las funciones como agentes del Estado y funcionarios. Por otro lado, elementos de lo personal de estos hombres y mujeres, existiendo un solapamiento de las distintas instancias. El poder pensar el papel de los agentes en entramados variables permite complejizar los trabajos historiográficos a partir de recuperar las redes de sociabilidad. La escritura de documentos del género "cartas" debe ser entendida como una práctica en sí misma. Los epistolarios son un tipo de fuente específico. En estos fondos también se visualiza la práctica del coleccionismo, la organización de la logística para expediciones arqueológicas y antropológicas y las relaciones institucionales con otros museos ( el Museo Etnográfico "Juan B. Ambrosetti" de la Facultad de Filosofía y Letras de la Universidad Nacional de Buenos Aires, el Museo "Bernardino Rivadavia de Ciencias Naturales", el Museo de La Plata, el Museo de Trenque Lauquen ,el museo "Emma Nozzi" de Carmen de Patagones y asociaciones científicas. Asimismo son de interés las relaciones con otras instituciones nacionales como el Ministerio de Agricultura, el Ministerio de Defensa o el Círculo Militar. 
El material producido por miembros de la Campaña del Desierto y los exploradores y científicos, ha quedado resguardado en gran parte por donaciones de sus familiares, y están a disposición en esta ambigua relación archivo-biblioteca-museo. Estos materiales permiten reconstruir las expediciones, y el trabajo de geógrafos y especialistas en la navegación de ríos y lagos, y en el relevamiento del relieve y la climatología. Se resguardan también en la institución documentación y registros de las comisiones de Límites y la de Estudios Hidrológicos.

\section{Palabras finales}

Los museos constituyen espacios donde la memoria ha pasado de tener un significado fijo a convertirse en lugares de investigación y procedimientos didácticos, donde los anclajes temporales son relatos que se modifican en el tiempo y responden a los grupos que han legitimado determinados proyectos, normas y valores. Es necesario entonces preguntarse por los objetivos de las gestiones de tamaños anclajes patrimoniales hoy y cómo ha sido su adaptación, si la hubo, en distintas épocas. Estas instituciones también pueden ser pensadas como lugares donde tienen lugar micropoderes, desde la conformación de los equipos, la producción científica, las decisiones de exhibición, la cartelería, las políticas de comunicación (Bennett 2005). Estas instancias se transforman en papel como consecuencia de normas burocráticas de gestión y de la necesidad de orden, de inventariar y de comunicar las acciones internas del museo. Estos archivos administrativos están siendo considerados para escribir estas biografías institucionales y ampliar el mapa de la práctica de la ciencia y de la cultura en distintas regiones del país.

Desde el punto de vista de la propia institución, desde perspectivas teóricas como la "nueva museografía", se han producido cambios en las maneras de concebir el patrimonio, y su contacto con la sociedad ha generado una apertura en el Museo de la Patagonia a partir de muchos proyectos relacionados con sus visitantes. Esto ha ampliado los públicos interesados por el Museo y ha permitido también el ingreso de diversos investigadores que permanentemente se acercan a la institución. Muchas veces las acciones del Museo y el Archivo no han estado ajenas a ciertas tensiones, incluyendo la diversidad de criterios de gestión, sin embargo las oportunidades de trabajo que brindan estas colecciones son infinitas.

\section{BIBLIOGRAPHY}

Bennett, T. (2005). Civic laboratories: museums, cultural objecthood, and the governance of the social. Cultural Studies, 19 (5), 521-547.

Caldo P. y Fernández S. (2009). Por los senderos del epistolario: las huellas de la sociabilidad. Antíteses, 2 (4), 1011-1032.

Demarchi, E. I. (2015). De una casa a una caja, de una carpeta a una pantalla. La digitalización de Archivos Históricos. Naturaleza y Tecnología, 15(65), 34-35. 
Farro, M. (2013). Esas redes que la razón ignora. Archivos y colecciones en la "biografía" institucional del Museo de La Plata. Revista Electrónica de Fuentes y Archivos, 4(4), 76-84.

García, S. (2012). Ficheros, muebles, registros, legajos: la organización de archivos y de la información en las primeras décadas del siglo XX En T. Kelly e I. Podgorny (Eds.), Los secretos de Barba azul. Fantasías y realidades de los archivos del Museo de La Plata, (pp. 37-61). Rosario: Prohistoria. .

Hedstrom, M. y King, J. L. (2006). Epistemic Infrastructure in the Rise of the Knowledge Economy. En B. Kahin y D. Foray (Eds.), Advanced Knowledge and the Knowledge Economy, (pp. 113-134). Cambridge, Mass.: MIT Press. Disponible en línea: http://jlking.people.si.umich.edu/ EpistemicInfrast-MITPress.pdf

Kelly, T. y Podgorny, I. (2012). Los secretos de Barba azul. Fantasías y realidades de los archivos del Museo de La Plata. Rosario: Prohistoria.

Mosches, E., Piantoni, G. y Pierucci, L. (2016). Estudios de caso: Museo de la Patagonia Francisco P. Moreno, Poblado Histórico de Colonia Suiza y Casa Museo de los Viejos Colonos. En L. Méndez y A. Podlubne (Dir.), Tiempo de jugar, tiempo de aprender. Educación, museos y prácticas corporales en la Patagonia norte. 1910-1955, (pp. 95-109). Buenos Aires: Prometeo.

Piantoni, G. (2015). Templos Cívicos del Saber. El Museo de la Patagonia en el contexto de la creación de la Dirección de Parques Nacionales (1934-1944). Tesis de Licenciatura, Universidad Nacional del Comahue, Facultad de Humanidades, Licenciatura en Historia, Sede San Carlos de Bariloche.

Piantoni, G. (2016). Subjetividades, instituciones y memoria: el Museo de la Patagonia como escenario. En L. Méndez y A. Podlubne (Dir.), Tiempo de jugar, tiempo de aprender. Educación, museos y prácticas corporales en la Patagonia norte. 1910-1955, (pp. 111-131). Buenos Aires: Prometeo

Pegoraro, A. y Spoliansky, V. (2013). El archivo del Museo Etnográfico Juan B. Ambrosetti: documentos para la historia institucional y disciplinar. Revista Electrónica de Fuentes y Archivos, 4 (4), 180-189.

Podgorny, I. (2011). Fronteras de papel: archivos, colecciones y la cuestión de límites en las naciones americanas. Historia Crítica, 44, 56-79.

Podgorny, I. (2013). Presentación Dossier Los archivos de la ciencia: prácticas científicas, cultura material y organización del saber. Revista Electrónica de Fuentes y Archivos, 4 (4), 16-23.

Pupio, A. (2011). Coleccionistas, aficionados y arqueólogos en la conformación de las colecciones arqueológicas del Museo de La Plata, Argentina (1930-1950). En A. Heizer y M. Lopes (Comps.), Coleccionismos, Prácticas de campo e representações, (pp.269-280). Paraíba: Universidad Estadual da Paraíba.

Pupio, A. (2013). Archivos para una historia práctica de la arqueología. Revista Electrónica de Fuentes y Archivos, 4(4), 24-33.

\section{NOTES}

1. El presente trabajo ha sido escrito a partir de un Informe Técnico elevado a la Administración de Parques Nacionales sobre el estado actual del Archivo Documental del Museo de la Patagonia en el Parque Nacional Nahuel Huapi. 


\section{ABSTRACTS}

Objects, in order to become scientific objects, require to be processed into paper. The practice of science as it is known today would not exist without the role that favored the exchange and circulation of objects, ideas and books, the formation of collections and catalogs, registration of fieldwork, the instruction of observers and their answers. Thanks to the corpus of documents that have survived today, institutional histories can be reconstructed, but also scientific sociability networks, including the relationship between teachers, correspondents and traders of natural history objects.

In this regard, and given that today the production spaces of local and regional stories are revalued, and that this will bring out the documentary records of such spaces, understanding that the documentary resource is the fundamental basis of historical research, and said material provides fragments of the past that must be analyzed and collated by researchers attempting to approach the past, and in order to survey the Documentary Administrative and Historical Archive of de Administration of Nationals Parks, in the Patagonia Museum "Dr. Francisco P. Moreno", this paper proposes a journey through the history of the institution, a brief state of the art, its challenges and opportunities.

Los objetos, para constituirse en objetos científicos, requirieron de su transformación en papel. La práctica de la ciencia como se la conoce hasta ahora no existiría sin el papel que favoreció el intercambio y circulación de objetos, ideas y libros, la formación de colecciones y sus catálogos, el registro del trabajo de campo, la instrucción a los observadores y la obtención de sus respuestas. Gracias al corpus de documentos que ha sobrevivido, hoy se pueden reconstruir historias institucionales, pero también las redes de sociabilidad científica, incluyendo la relación entre los profesores, los corresponsales y los comerciantes de objetos de historia natural.

Con el objetivo de relevar el Archivo Documental, Administrativo e Histórico de la Administración de Parques Nacionales en el Museo de la Patagonia "Dr. Francisco P. Moreno", este trabajo propone un recorrido por la historia de la institución, un breve estado de la cuestión, sus desafíos y oportunidades.

\section{INDEX}

Palabras claves: Museo, Archivo, Patagonia, Digitalización, Estado nacional

Keywords: Museum, Archive, Patagonia, Digitization, National State

\section{AUTHORS}

\section{GIULIETTA PIANTONI}

Instituto de Estudios de Humanidades y Ciencias Sociales - Unidad Ejecutora del Consejo Nacional de Investigaciones Científicas y Técnicas - Universidad Nacional del Comahue Correo electrónico: piantonigiulietta@gmail.com 


\section{MARÍA ALEJANDRA PUPIO}

Departamento de Humanidades (UNS)/CIC, Provincia de Buenos Aires Correo electrónico: mapupio@uns.edu.ar 